http://www.jfas.info

\title{
THE EFFECTIVENESS OF COGNITIVE-BEHAVIORAL GROUP COUNSELING ON STRESS AND SELF-EDUCATION
}

\author{
O. Khoshniyat ${ }^{1}$, B. Monfaredi $\operatorname{Raz}^{2}$ and E. Alizade Mousavi ${ }^{2}$ \\ ${ }^{1}$ MA Student in School Counselling, Quchan Branch, Islamic Azad University, Quchan, Iran \\ ${ }^{2}$ Assistant Professor of Educational Sciences Department, Farhangian University of Bojnord, \\ Iran
}

Published online: 15 May 2016

\begin{abstract}
The purpose of this article is studying the effectiveness of cognitive-behavioral group counseling on stress and self-efficacy in second grade female students studying in a high school of Shrvan County. This research is a pre-test and post-test experimental design along with the control group. The statistical population is all 15-18 years-old second grade female students studying in a high school of Shirvan County in 2015-2016. 30 subjects were selected in the form of multistep cluster as the sample size. Data collection tool is Morgan- Jinks (MJSES) Student Efficacy Scale Questionnaire and critical academic stress (1993). Data were analyzed using variance analysis method. The results showed that cognitive-behavioral group counseling was significant on stress and academic self-efficacy. This means cognitive-behavioral counseling enhances the academic efficacy and reduces the student stress.
\end{abstract}

Keywords: Education efficacy; education stress; cognitive-behavioral counseling.

Author Correspondence, e-mail: authorC@ gmail.com

doi: http://dx.doi.org/10.4314/jfas.v8i3s.188 


\section{INTRODUCTION}

According to the extensive educational problems and the importance of these issues among the students on one hand and the educational, social, psychological and health consequences of these problems on the other hand, the students would face with irreparable failures if the appropriate intervention is not done. Business achievement and education self-efficacy by students has always been a great goal of formal education system. Efficacy is derived of Albert Bandura social cognitive theory (1997) that refers to the individual's beliefs to the ability for performing the duties and responsibilities. The individual's efficacy and his attitude and perception of himself have a close relationship with how he learns and behaves (Tella, 2011).

To Bandura, self-efficacy is the most basic human mechanism necessary for the management and control of events that affect his life (Zimmerman B. \& Kitsantas A. 2005). High self-efficacy is related with mental health and low self-efficacy is related with depression and anxiety symptoms and the psychosomatic symptoms (Bandura, 2004). Self-efficacy plays an important role as a mechanism to facilitate the mental health. Self-efficacy as a mediator facilitates the compatibility of students who are experiencing the stress. The Students' beliefs about their effectiveness affect both the management and demand regulation of education tasks and reduce of stress (Zirman, 2004). Self-efficiency affect not only how organizing the threats, but people's compatibility with them. High self-efficacy reduces the confusion against the stressful events (Marino, 2008).

Self- efficacy makes a difference in how someone feels, thinks and acts. In the case of sense, low self-efficacy is related to depression, anxiety and low self-esteem and in the case thoughts, high self-efficacy facilitates cognitive processes and education performance. Finally, there is a direct relationship between self-efficacy and motivation for action (Golteglee, 2007). The studies show a significant positive relationship between personal effectiveness and education performance. Teachers with a high degree of efficacy in their teaching abilities create more opportunities for students' successful performance (Nistol, 2010). Self-efficacy beliefs have a positive relationship with education achievement. Self- efficiency also affects the learning and education achievement (Shank, 2008). Self-efficacy affects choosing the activities, the effort, 
endurance and perseverance in carrying out and achievement of the assignments. Self-efficacy is also the factor that plays a major role in education performance. Students with high self-efficacy achieve more progress compared to the students with low efficiency.

Over the past decade, studying the stressful education experiences among the students has considerably expanded. Educational activities for children and teenagers is very important in most cultures but parents, teachers and students' expectations due to the competition and education hegemony can be a source of stress for the most students (Tan \& Yates, 2011). A survey has shown that the most teens (67 percent of teens) consider the education pressures as the biggest stress in their lives (Tan \& Yates, 2011). If the education stress intensifies or continues, it causes some problems for people in the case of mental health and well-being. The studies indicate the relationship between high education expectations and education stress among students (Ang, Klassen, Chong, Huan, Wong, Yeo \& Rawchuk). The other psychological problems associated with education stress include depression, anxiety and behavioral problems (Don, 2010). Researches done in the field of education stress highlight the role of students' expectations and the others' expectations (Ang \& Huan, 2006).

Education stress refers to individual's assessment based on the experience of incompatibility between situational demands and resources within own individual. The evidences have shown that an educational problem is one of the most common sources of education stress in the students. Students could be divided into two parts: education stress caused by parents and teachers' expectations and education stress due to personal expectations (Don, 2010).

Group counseling process includes group discussion and training and all cognitive-behavioral strategies. The main goal is helping the members of group to identify their feelings and experience and understand their default impact on how feelings and behaviors an experience another alternative behaviors. What is emphasized in the group is the role of every member's responsibility in helping to members and own to focus on own thinking, feeling and behavior and try to change it. Features of cognitive-behavioral approaches such as experimental and participation work relationship, being active, purposefulness, focused on the problem, teaching the coping skills and the emphasis on feedback are very appropriate for the treatment of teen clients (Skott and Fitter Jrald, 1987'; Translated by Khodayari Fard, 2007). 
Cognitive-behavioral therapists teach the members of group that they themselves are responsible for their own problems and disorders and help them to recognize the process of self-talk that causes their problems continue and leave them and in the Group, irrational thoughts are gone and replaced by rational thoughts. The counsel in these groups often have an especial role and does his work using logic, persuasion, playing role, giving assignments and the other numerous ways so from a scientific perspective, it seems that three important changes occur in the cognitive group counseling program:

1- Changes that occurs in more stable cognitive structures (schema).

2- Changes in thought processes that at first are deliberately and consciously projected. Arch, Ayers, Baker, Almko, Dion and Krask (2013), studied about the effect of cognitive-behavioral management of stress on education stress. The results showed that cognitive-behavioral management causes reduction of mood disorders, stress, tension and anxiety among the people. Cognitive-behavioral management of stress has a significant impact on reducing the students' stress. Bryan, Gartner, Wertenberger \& Delano (2012), studied about the effect of cognitive-behavioral management of stress and cognitive therapies on reduction of the students' stress, depression and anxiety. The results showed that cognitive-behavioral management of stress causes cognitive-behavioral management causes reduction of mood disorders, stress, tension and anxiety among the people. Therefore, cognitive-behavioral management of stress has a significant impact on reducing the students' stress.

Johani (2010), studied about the effectiveness of cognitive-behavioral counseling on students' self-efficacy. The study was applied and the quasi-experimental type with pretest-posttest design of control group. The results showed that the students estimated high their self-efficacy level after training compared to before of training. According to the above, it can be said that cognitive-behavioral counseling helps to students to overcome the difficulties, cope with various life situations, improve conditions, assess their progress, take responsibility for their actions and reach to education success and self-efficacy by strengthen the self-esteem. Thus, this study is going to answer this question:

Does the cognitive-behavioral counseling method cause to reduce the stress and increase the 
education efficacy?

\section{METHOD}

The study was applied and the non-equivalent pretest-posttest control group design. The statistical population is all 15-18 years-old second grade female students studying in a high school of Shirvan County in 2015-2016. 30 subjects were selected in the form of multistep cluster as the sample size. This means that among 8 high schools, 2 schools were randomly selected and 4 classes including 100 people answered to education stress and education self-efficacy questionnaire. 60 people got high score in education stress questionnaire and low score in education self-efficacy questionnaire and Then, 30 subjects were randomly selected and were randomly assigned in experimental and control groups (15 people in experiment group) and (15 people in control group).

\section{RESEARCH TOOLS}

Morgan- Jinks Student Efficacy Scale Questionnaire (MJSES): It is the most extensive questionnaire that uses its report levels as a dependent variable. The questionnaire has 30 questions and 3 subscales, talent (13 questions), attempts (4 questions) and texture (13 questions). The questions of the questionnaire were designed with talent, texture and effort issues using Likert scale with multiple choice answers including totally disagree, somewhat disagree, somewhat agree and strongly agree that respectively have 1, 2, 3 and 4 scores. Morgan and Jinks (1999) have reported reliability coefficient of the questionnaire 0.82 and reliability coefficient of each talent, texture and effort subscales $0.78,0.66$ and 0.70 respectively. In order to check the validity of education self-efficacy quesionnaire, Morgan and Jinks used the factors analysis. Factor analysis has three main factors in highlighted scale. The researchers have reported significant at the moderate level the items correlated with the total score of the questionnaire. Since the cut-off point has not been set for this questionnaire, students' education self-efficacy was divided into three scales (low education self-efficacy, medium education self-efficacy and high education self-efficacy), so that 30 to 60 score represent the low education self-efficacy, 61-90 score represent the medium education 
self-efficacy, 91-120 score represent the high education self-efficacy.

Education Expectations Stress Inventory (ASI): Ang and Huang (2006) have prepared the questionnaire to assess teenagers' education sources of stress. This test with 9 questions has two subtests: stress test caused by parents / teachers' expectations and stress caused by their personal expectations. The questions such as: 1- When I cannot meet the expectations of my parents, I blame myself, 2- When I do not perform well in school, I feel like I've disappointed my teacher. The questions in the case of stress test caused by parents/teachers' expectations such as: When I do not work myself up to expectations, I feel I did not a good performance. Higher scores mean higher stress and vice versa. Cronbach's alpha for this test is reported between 0.79 and 0.90 and two weeks retest reliability between 0.77 and 0.85 . This scale is normalized on normal and talented students (Mirshahvalad, 1992).

\section{FINDINGS}

Table 1. Covariance Analysis of education stress in experiment and control group with pre-test control

\begin{tabular}{cccccccc}
\hline Eta & $\begin{array}{c}\text { Significanc } \\
\text { e Level }\end{array}$ & F & mean & Freedo & $\begin{array}{c}\text { Sum of } \\
\text { squares }\end{array}$ & $\begin{array}{c}\text { Source of } \\
\text { mquares }\end{array}$ & $\begin{array}{c}\text { distribution } \\
\text { Degree }\end{array}$ \\
\hline $0 / 031$ & $0 / 275$ & $1 / 229$ & $0 / 419$ & 1 & $0 / 419$ & Pre-test of \\
& & & & & & education stress \\
\hline $0 / 627$ & $0 / 001$ & $14 / 09$ & $214 / 34$ & 1 & $214 / 34$ & Group \\
\hline & & & $3 / 221$ & 29 & $122 / 411$ & Error \\
\hline
\end{tabular}

As shown in Table 1, there is a significant difference between the girls in experiment group and girls in control group in terms of education stress score. So the first main hypothesis is confirmed. In the other words, there is a significant difference between education stress among the girls in experiment group and girls in control group by ignoring the pre-test effect $(\mathrm{p}<0.00$ and $\mathrm{f}=14.09)$. Girls' education stress score has been decreased. In addition, the effect 
or difference is 0.627 that means62 percent of individual differences in the posttest (education stress score) is related to the impact of the intervention. So according to Table 2-4, it can be concluded that the girls who received cognitive-behavioral group counseling (experiment group) have experienced more education stress rather than the girls in the control group.

Table 2. Covariance Analysis of education self-efficiency in experiment and control group with pre-test control

\begin{tabular}{|c|c|c|c|c|c|c|}
\hline Eta & $\begin{array}{c}\text { Significanc } \\
\text { e Level }\end{array}$ & $\mathbf{F}$ & $\begin{array}{c}\text { mean } \\
\text { squares }\end{array}$ & $\begin{array}{c}\text { Freedo } \\
\text { m } \\
\text { Degree }\end{array}$ & $\begin{array}{l}\text { Sum of } \\
\text { squares }\end{array}$ & $\begin{array}{l}\text { Source of } \\
\text { distribution }\end{array}$ \\
\hline $0 / 328$ & $0 / 219$ & $0 / 858$ & $3 / 805$ & 1 & $3 / 805$ & $\begin{array}{c}\text { Pre-test of } \\
\text { controlling } \\
\text { emotions }\end{array}$ \\
\hline \multirow[t]{2}{*}{$0 / 561$} & $0 / 041$ & $37 / 06$ & $97 / 23$ & 1 & $97 / 23$ & Group \\
\hline & & & $4 / 435$ & 29 & $172 / 95$ & Error \\
\hline
\end{tabular}

As shown in Table 2, there is a significant difference between the girls in experiment group and girls in control group in terms of education self-efficiency score. So the second main hypothesis is confirmed. In the other words, there is a significant difference between self-efficiency among the girls in experiment group and girls in control group by ignoring the pre-test effect $(\mathrm{p}<0.00$ and $\mathrm{f}=37.06)$. Girls' education stress score has been increased. In addition, the effect or difference is 0.561 that means 26 percent of individual differences in the posttest (education stress score) is related to the impact of the intervention. So according to Table 4-6, it can be concluded that the girls who received cognitive-behavioral group counseling (experiment group) have experienced more education self-efficiency rather than the girls in the control group.

\section{CONCLUSION}

With beginning of the high school, the curriculum both in terms of content and complexity of 
the content that is taught to students get much heavier than the junior high school. The high volume and heavy contents cause the education stress. Furthermore, the students have the entrance exam test in the future that it can determine the future course of their life. Success in the exam as the first step on the path to higher education can facilitate the access to jobs and partially acceptable social status. The failure is for students and their families can be considered as the loss of social status, unemployment and so on. All these factors increase the expectations of success in school (As well as students' expectations and the expectations of their parents about educational status of children). Although these expectations can be reasonably encourage the students to do more attempts in the field of higher education and improve their education performance. But if the education expectations (both their expectations and the expectations of parents) exceed the limit, it causes the stress in the students and affects their education performance and mental health. The researches done in the field of education expectations stress is very low. In the field of effect of stress management on students' education expectations stress has not been done many researches. Cognitive-behavioral counseling behavioral strategies such as relaxation and muscle relaxation reduce the stress and anxiety. People identify the physical symptoms associated with the stress and reduce the stress and tension due to education expectations by mastering in business with the peace that is incompatible with stress (Azad, 2011). Identifying the negative automatic thoughts and cognitive distortions has the important role in reasonable evaluation of stressors. People learn to make sound evaluation of their educations talents and abilities have the reasonable expectations in relation to success in the field of education and based on correct this assessment correct. These reasonable expectations reduce the stress and thus increase the probability of success.

\section{AKNOWLEDGMENT}

This work was supported by Quchan Branch, Islamic Azad University and was part of a master student dissertation No. 204. 


\section{REFRENCES}

[1] Stenberg R. (2009), cognitive psychology, Translated by Seyyed Kamal Kharazi \& Elahe Hejazi, The Study and Compilation of Humanities Books Organization (SAMT).

[2] Baghani M. Dehghani Neyshabouri M. (2011), The effect of education motivation, self-efficiency and approaches of study on students' achievement, National Conference on findings of cognitive science in Education, 3, 2, 113-121.

[3] Broucheska, L.E (2007), cognitive psychology, Translated by Parvin Kadivar \& Mohammad Jafar Javadi, Tehran, ROSHD.

[4] Haji Mirzaie M. (2010), Investigate the relationship between creativity and education self-efficiency on attitude to school in female students in regular and boarding schools, MA Thesis, Psychology and Educational Sciences Faculty, Tehran University.

[5] Hajati F. Akbarzade N. Khosravi Z. (2008), The effect of cognitive behavioral therapy program combined with a positive approach on the prevention of teenagers' violence in Tehran, Psychological studies, Course 4, No. 3, 35-56.

[6] Hejazi E. Farsinejad M. Askari A. (2007), the identity styles and education achievement, the role of education self-efficacy, Scientific-Research Psychology Journal, 11, 44; 394-413.

[7] Hejazi E. Naghsh Z. (2008), The structural model of the relationship of perception of classroom, Achievement goals, Self-Efficiency, Self-regulation in math, Cognitive Science News, 10 (4), 27-37.

[8] Hassanpour Gharechal J. (2010), Relationship of Parenting Styles, education conscience and education self-efficacy with education achievement, MA Thesis, Psychology and Educational Sciences Faculty, Tehran University.

[9] Khadivari A. Vakili Mafakheri A. (2011), The relationship of achievement motivation, Control Source, Self-efficacy and education achievement of first-year students in high school of Tabriz City, Education, 4 (13), 45-46.

[10]Dehghani F. Neshatdoost H. Molavi H. Nilforoushzade M. (2009), The effectiveness of cognitive behavioral stress management therapy on quality of patients' life with alopecia areata in Skin Disease and Leishmaniasis Research Center, Isfahan, Medical Sciences 
University of Arak, 12, (2), 125-133.

[11]Ranjbar F. Ashk Torab T. Dadgari A. (2010), the effectiveness of cognitive behavioral group therapy on depression, Sicentific-Research Medical Sciences Journal of Yazd Sedoughi Martyr, 2010, 18 (3), 299-306.

[12]Rajabi G. (2006), studying the validity and reliability of general self-efficacy beliefs, Training new ideas, (68), 1, 93-95.

[13]Zareb G. (2007), Assessment and cognitive behavioral therapy in teenagers, Translated by Khodayarifard M. and Abedini Y. Tehran, Tehran University Publication.

[14]Zeynalipour H. Zareie E. Zandinia Z. (2009), General and Education self-efficacy of students and its relationship with education performance, Educational Psychology Journal, $6(9), 14-25$.

[15]Samadi A. (2007), The relationship between perception of support from family, teachers and friends and self-efficacy and education achievement in high school students, Master's Thesis, Psychology and Educational Sciences Faculty Ma Thesis, Allameh Tabatabaei University.

[16]Abasianfard M. Bahrami H. Ahghar G. (2011), studying the relationship between self-efficacy and motivation in pre-university students, Applied Psychology Journal, 4 (1), 95-109.

[17]Isazadegan A. Dastouri R. and Abdeli Soltan Ahmadi J. (2012), The effectiveness of neuro-linguistic programming strategies on self-efficacy, anxiety and motivation of pre-university school students' achievement, Psychological studies, 8 (4), 73-94.

[18]Ghafari A. Arfa Balouchi F. (2011), studying the relationship between achievement motivation and education self-concept and test anxiety among graduate students at Ferdowsi University of Mashhad, Clinical Psychology Research and Consulting, 1 (2), 121-136.

[19]Fatehi Y. (2011), studying the relationship between education self-efficacy and study habits in high school students in Shiraz, Psychology master's thesis, Education and Psychology Faculty, Ferdowsi University of Mashhad.

[20]Free M. (2003), group therapy cognition, Translated by Sahebi A. et al. Mashad, SID 
Publication.

[21] Karimzade M. and Mohseni N. (2006), The relationship between education self-efficacy and education achievement in high school female students of Tehran, women Studies, 4 (2), 29-45.

[22] Karimzade M. and Mohseni N. (2006), the relationship between education self-efficacy and education achievement in high school female students of Tehran, women Studies Journal, 4 (2), 29-45.

[23] Golman D. (1995), Emotional Intelligence, Translated by Parsa N. Tehran, Roshd

[24]Kouri J. (2008), Theory and practice of counseling and psychotherapy, Translated by Seyyed Mohammadi, Tehran, Arasbaran, publication date of original work 2001.

[25]Kouri J. (2011), compilation Consulting Art, (Translated by Etemadifar), Tehran, publication date of original work 2001.

[26]Kouri Mrian E. Kouri J. (2012), Therapy Group, Translated by Bahari B. Ranjgar H. Naghshbandi S.) Tehran, Ravan.

[27]Lotfi Kashani F. (1998), integrated strategies in counseling and psychotherapy, Psychology and Education Journal, Tehran University, No. 57.

[28]Lavasani M. Ajehie J. Afshari M. (2009), Studying the relationship between education self-efficacy and engagement with education achievement, Psychology Journal, 13 (3), 290-302.

[29] Mohsenpur M. Hejazi E. Kiamanesh A. (2007), The role of self-efficacy, Achievement goals, Learning strategies and sustainability in education achievement in third grade of high school students in math, Tehran, Educational Innovations Journal, 5 (16), 9-35.

[30] Amini M. Narimani M. Berahman O. Sobhi Gharamaleki N. (2008), the relationship between emotional intelligence and mental health and compare them in successful and ordinary students, Knowledge and research in psychology, 35 \& 36, 107-122.

[31]Mir Moshtaghi S. (2005), Assess and compare the self-efficiency and self-regulation with students' education achievement, Third grade math and physics and humanities courses of high schools in Tehran, Master's Thesis, Psychology and Educational Sciences Faculty, Al-zahra University. 
[32]Nikrouie A. (2003), Studying the relationship between general self-efficacy and mental health of high school third grade students in Babol, Basic psychology master's thesis, Allameh Tabatabaei University.

[33]Hawton K. et al. (2010), Cognitive therapy behavior, (Translated by Ghasemzade H.), Tehran, Arjmand Publication.

[34]Ang, R. P., Klassen, R. M., Chong, W. H., Huan, V. S., Wong, I. Y. F., Yeo, L. S., \&Krawchuk, L. L. (2009). Cross-cultural invariance of the Academic Expectations Stress Inventory: Adolescent samples from Canada and Singapore. Journal of Adolescence.32, 1225-1237.

[35]Ang, R. P., Huan, V. S., \& Braman, O. R. (2007). Factorial structure and invariance of the Academic Expectations Stress Inventory across Hispanic and Chinese adolescent samples. Child Psychiatry \& Human Development, 38(1), 73-87.

[36]Ang, R. P., \& Huan, V. S. (2006). Academic expectations stress inventory: Development, factor analysis, reliability, and validity. Educational and Psychological Measurement, 66(5), 522-539.

[37]Ang, R. P., \& Huan, V. (2006). Relationship between academic stress and suicidal ideation: Testing for depression as a mediator using multiple regressions. Child Psychiatry and Human Development, 37, 133-143.

[38]Bandura, A. (2007). Self-efficacy: The exercise of control. New York: Freeman.

[39]Bandura, A. (2007). Social foundation of thought and action: A social cognitive theory. Englewood Cliffs, NJ: PrenticeHall.

[40]Bandura, A. \& Locke, E.A. (2003) Negative Self- efficacy and goal revisited. Journal of Applied psychology. 88(1): 87 - 89

[41]Dunne, M. P., Sun, J., Nguyen, N. D., Truc, T., Loan, K. X., \& Dixon, J. (2010). The influence of educational pressure on the mental health of the adolescence in East Asia. Journal of science research, Hue University, 61(1), 18-27.

[42]Gadzella, B. M, \& Baloglu, M. (2001). Confirmatory factoranalysis and internal consistency of student-life stress inventory. J Instruc Psychol.6 (28), 84-94.

[43]Tella, A. (2011). An assessment of mathematics self - efficacy of secondary school 
students .in Osun state, Nigeria. IFE Psycholog, 19 (1), 430-440.

[44]Tan, J. B., \& Yates, Sh. (2011). Academic expectations as sources of stress in Asian Students. Soc Psychological Education, 14, 389-407.

\section{How to cite this article:}

Khoshniyat O, Monfaredi Raz B and Alizade Mousavi E. The effectiveness of cognitive-behavioral group counseling on stress and self-education. J. Fundam. Appl. Sci., 2016, 8(3S), 384-396. 